\title{
MAGNETIC AND TRANSPORT PROPERTIES OF $\left(\mathrm{Fe}_{1-x} \mathrm{Ni}_{x}\right)_{2} \mathrm{P}$ IN VIEW OF KKR-CPA RESULTS
}

\author{
S. KAPRZYK, S. NizIOL, J. TOBOLA
}

Faculty of Physics and Nuclear Techniques AGH

Al. Mickiewicza 30, 30-059 Kraków, Poland

R. ZACH

Institute of Physics, Technical University of Kraków

Podchorążych .1, 30-084 Kraków, Poland

M. Bacmann, D. Fruchart and P. Wolfers

Laboratoire de Cristallographie CNRS, BP-166X Grenoble Cedex 9, France

We present results of the electronic structure study for the solid solution $\left(\mathrm{Fe}_{1-x} \mathrm{Ni}_{x}\right)_{2} \mathrm{P}$ (space group $P \overline{6} 2 m$ ). The samples were synthesized for $x=0.0$ up to 0.15 . From the electrical conductivity measurements on these materials, it was verified that resistivity increases with increasing temperature up to the Curie point $T_{\mathrm{C}}$ and changes the slope at $T_{\mathrm{C}}$ decreasing when temperature is raised above $T_{\mathrm{C}}$. To get insight into the possible origin of such observations, we carried out the Korringa-Kohn-Rostoker-coherent potential approximation electronic structure calculations for $\left(\mathrm{Fe}_{1-x} \mathrm{Ni}_{x}\right)_{2} \mathrm{P}$ in the range of concentration $x=0.0$ up to 1.0. It was found that alloying with $\mathrm{Ni}$ in $\mathrm{Fe}_{2} \mathrm{P}$ causes vanishing of spin band splitting and non-rigid band behaving of electronic valence states near the Fermi level. The polarization factor for electrons at $E_{\mathrm{F}}$ changes in $\left(\mathrm{Fe}_{1-x} \mathrm{Ni}_{x}\right)_{2} \mathrm{P}$ with increasing $x$, and interestingly, it reaches maximum at $x=0.1$, closely to the concentration $(x=0.08)$, when the largest value of $T_{\mathrm{C}}$ and a kink in temperature dependent resistivity were detected.

PACS numbers: 71.20.Lp, 71.20.-b, 75.50.Cc

\section{Introduction}

The $\mathrm{T}_{2} \mathrm{D}$ hexagonal systems (space group $P \overline{6} 2 \mathrm{~m}$ ), where $\mathrm{T}$ represent $3 d$ $(\mathrm{Mn}, \mathrm{Fe}, \mathrm{Co}, \mathrm{Ni})$ or $4 d(\mathrm{Ru}, \mathrm{Rh})$ transition metal elements, and $\mathrm{D}$ are metalloids ( $\mathrm{Si}, \mathrm{P}, \mathrm{As}$ ), exhibit complex behaviour of some measured quantities. The structural, magnetic and transport properties were investigated by various experimental techniques (neutron diffraction measurements, Mössbauer effect, specific heat, electrical resistivity, magnetization measurements) $[1,2]$, as well as by the 
band theory methods [3-5]. In general, $\mathrm{T}_{2} \mathrm{P}$ compounds form solid solutions with the same crystal structure. Nevertheless, when alloying with others metalloids, e.g. as in $\mathrm{MnFeP}_{1-x} \mathrm{As}_{x}$, or as in $\mathrm{Fe}_{2} \mathrm{P}_{1-x} \mathrm{Si}_{x}$, the phase transition to orthorhombic structure is observed. The system $\left(\mathrm{Fe}_{1-x} \mathrm{Ni}_{x}\right)_{2} \mathrm{P}$ is particularly attractive in that class of materials. It is observed here that the Curie temperature $T_{\mathrm{C}}$ changes with increasing $x$ (at $x=0.1, T_{\mathrm{C}}$ reaches the maximum value), while the total magnetic moment decreases monotonically [6]. This experimental observation well corresponds to the temperature dependent electrical resistivity curves [6], which show clearly a kink around $T_{\mathrm{C}}$, the most distinct for $\left(\mathrm{Fe}_{0.9} \mathrm{Ni}_{0.1}\right)_{2} \mathrm{P}$ alloy. The present paper gives additional information on electronic structure of disordered $\left(\mathrm{Fe}_{1-x} \mathrm{Ni}_{x}\right)_{2} \mathrm{P}$ samples and reveals specific features on densities of states (DOS) at the Fermi level (highly spin-polarised state), which may affect transport phenomena (resistivity, magnetoresistance).

\section{Results and discussion}

We performed regular band structure studies of $\left(\mathrm{Fe}_{1-x} \mathrm{Ni}_{x}\right)_{2} \mathrm{P}$ (for $x=0.0$, $0.05, \ldots, 1.0)$ alloys using charge and spin selfconsistent Korringa-Kohn-Rostoker (KKR) method with the coherent potential approximation (CPA) $[7,8]$, designed to disordered systems. In fact, the $\mathrm{Ni}$ impurities were diluted on nonequivalent tetrahedral $(3 f)$ and pyramidal $(3 g)$ positions, thus the chemical formula $\left(\mathrm{Fe}_{1-x} \mathrm{Ni}_{x}\right)\left(\mathrm{Fe}_{1-y} \mathrm{Ni}_{y}\right) \mathrm{P}$ better corresponds to the studied system. At present, we restrict our calculations to the case when $x=y$ (no site preference in occupancy), which is not fully supported by neutron diffraction and Mössbauer studies [9]. The experimental crystal data determined for $\mathrm{Fe}_{2} \mathrm{P}$ system [5] were used in all computations for intermediate compositions. In Fig. 1 we see the concentration dependent total and atomic magnetic moment variations in $\left(\mathrm{Fe}_{1-x} \mathrm{Ni}_{x}\right)_{2} \mathrm{P}$ system. In pure $\mathrm{Fe}_{2} \mathrm{P}$ the local magnetic moment $2.33 \mu_{\mathrm{B}}$ on $\mathrm{Fe}(3 g)$ is almost three times larger than the one $0.83 \mu_{\mathrm{B}}$ on $\mathrm{Fe}(3 f)$ [5]. These values remain almost constant up to $x=0.5$. For higher concentration of $\mathrm{Ni}$ the local moments strongly drop, nevertheless $\mathrm{Fe}(3 g)$ impurities in $\mathrm{Ni}_{2} \mathrm{P}$ still maintain the magnetic moment $1.2 \mu_{\mathrm{B}}$,
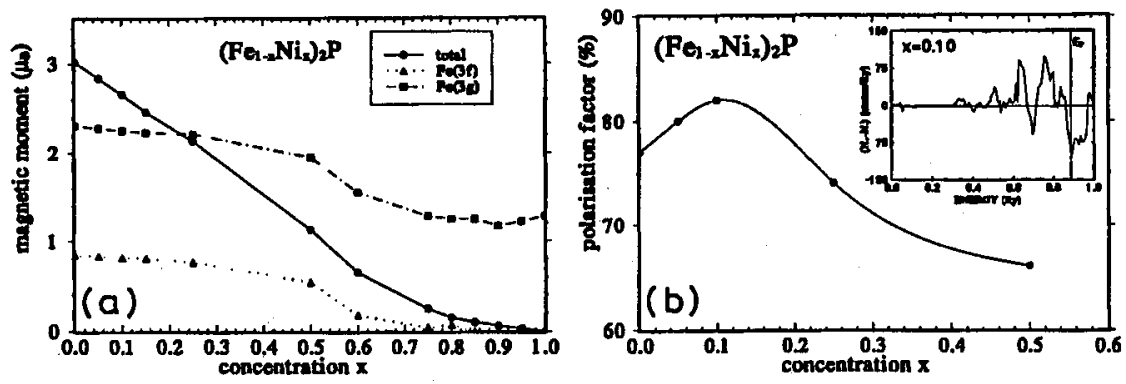

Fig. 1. (a) The total and atomic magnetic moments variations in $\left(\mathrm{Fe}_{1-x} \mathrm{Ni}_{x}\right)_{2} \mathrm{P}$ system calculated from-CPA method. (b) The concentration dependent polarization factor $P$ of electrons at $E_{\mathrm{F}}$. In the top-right corner, the energy distribution of the total magnetic moment $\Delta N(E)$ for $\left(\mathrm{Fe}_{0.9} \mathrm{Ni}_{0.1}\right)_{2} \mathrm{P}$ is shown. 
while $\mu_{\mathrm{Fe}}$ on (3f) site indeed disappears. From the previous magnetization measurements [6], the samples with $x$ above 0.8 exhibit zero magnetization. At this composition the iron atoms are probably diluted too much to preserve ferromagnetic (FM) ordering. The site preference in occupancy may also result into the quicker dropping of the total magnetic moment. The KKR calculations performed for ordered $\mathrm{FeNiP}$ (Fe at tetrahedral site, $\mathrm{Ni}$ at pyramidal site) and $\mathrm{NiFeP}(\mathrm{Ni}$ at tetrahedral site and $\mathrm{Fe}$ at pyramidal site) show significantly different magnetic moments (total and atomic): $2.91,0.86,0.20$ and $4.18,-0.12,1.59$ (in $\mu_{B}$ ), respectively. In $\mathrm{FeNiP}$ the $\mu_{\mathrm{Ni}}$ has parallel alignment to the $\mu_{\mathrm{Fe}}$, while in $\mathrm{NiFeP}$ compound $\mathrm{Ni}$ atoms possess small negative magnetic moment. From the KKR-CPA computations for the disordered $\left(\mathrm{Fe}_{1-x} \mathrm{Ni}_{x}\right)_{2} \mathrm{P}$ system, we see no magnetic moment on $\mathrm{Ni}$ atoms in the whole range of $x$ concentration. In this context a polarised neutron diffraction studies will be very helpful to distinguish the atomic contributions to the total magnetic moment. Also the total energy KKR-CPA analysis of systems $\left(\mathrm{Fe}_{1-x} \mathrm{Ni}_{x}\right) \mathrm{FeP}, \mathrm{Fe}\left(\mathrm{Fe}_{1-y} \mathrm{Ni}_{y}\right) \mathrm{P}$ and $\left(\mathrm{Fe}_{1-x} \mathrm{Ni}_{x}\right)_{2} \mathrm{P}$ is projected to observe the possible onset of site preference with Ni substitution. In Fig. 2 we present the evolution of electronic structure in $\left(\mathrm{Fe}_{1-x} \mathrm{Ni}_{x}\right)_{2} \mathrm{P}$ system. At the first sight, we observe striking differences of DOS curves at the Fermi level. For the spin-up electrons the $E_{\mathrm{F}}$ lies in a deep valley, while for the spin-down a large peak of DOS at $E_{\mathrm{F}}$ is seen.

\section{$\left(\mathrm{Fe}_{1-\mathrm{x}} \mathrm{Ni}_{\mathrm{x}}\right)_{2} \mathrm{P}$}
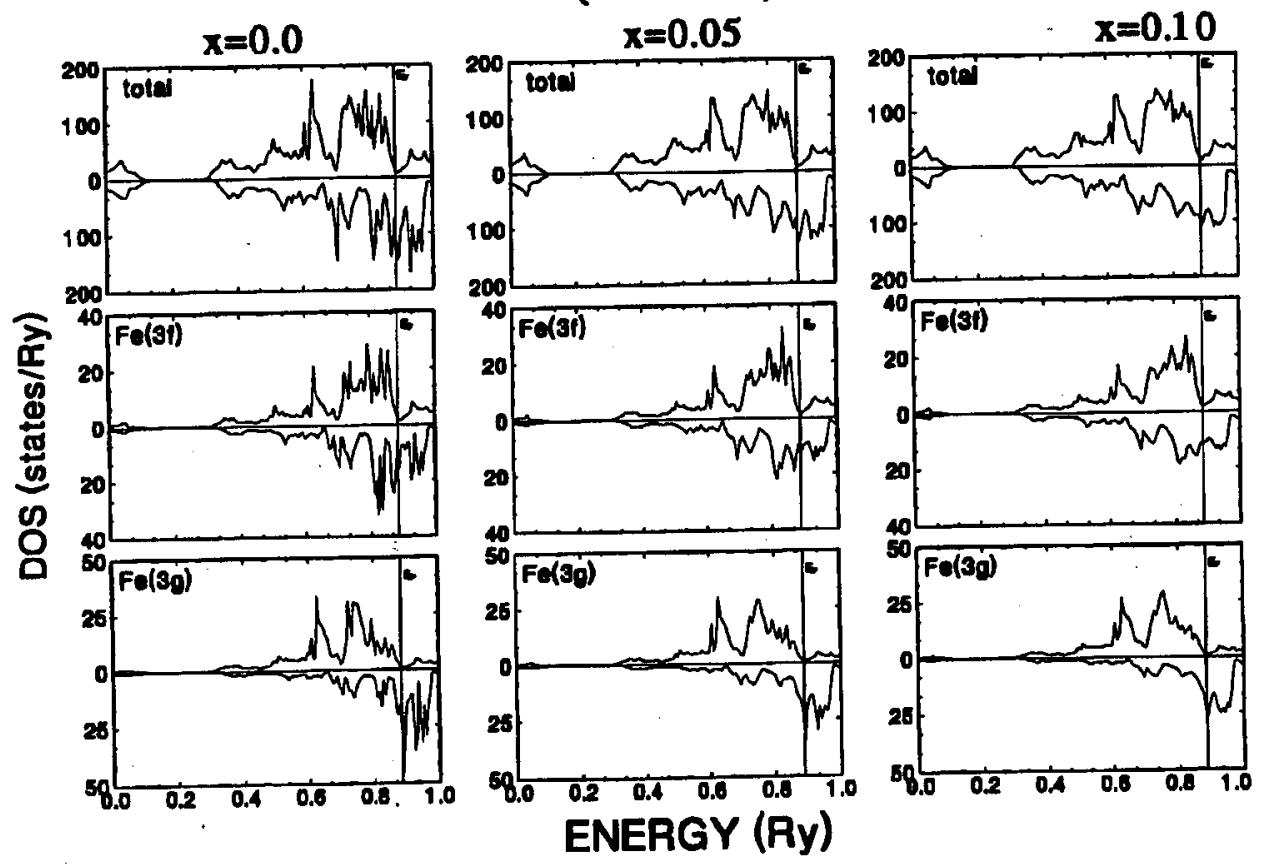

Fig. 2. The spin-projected total and component DOS for $\left(\mathrm{Fe}_{1-x} \mathrm{Ni}_{x}\right)_{2} \mathrm{P}(x=$ $0.0,0.05,0.1$ ). 
When performing the energy dependent distribution of total magnetic moment, defined as $\Delta N(E)=N_{+}(E)-N_{-}(E)$, we observe that conduction electrons near $E_{\mathrm{F}}$ possess opposite spin to the $\mu_{\text {tot }}$, due to the large spin-down $3 d$-DOS peak seen on $\mathrm{Fe}(3 g)$. With an increase in $\mathrm{Ni}$ in $\left(\mathrm{Fe}_{1-x} \mathrm{Ni}_{x}\right)_{2} \mathrm{P}$, we observe vanishing of spin band splitting and non-rigid behaving of valence bands near the Fermi level. Considering our electrical resistivity data of hexagonal systems as well as for instance $\mathrm{Fe}_{3-x} \mathrm{~V}_{x} \mathrm{Si}$ Heusler system [10], some common features can be noticed such as a maximum on resistivity curve $R(T)$ close to $T_{\mathrm{C}}$. The DOS curves of $\mathrm{Fe}_{3-x} \mathrm{~V}_{x} \mathrm{Si}$ system is close to the half-metallic ferromagnets, which exhibit $100 \%$ polarization of electrons at $E_{\mathrm{F}}$ (a gap for one spin direction). Using the polarization factor $P$, defined as $P=\left|\frac{N_{+}\left(E_{F}\right)-N_{-}\left(E_{F}\right)}{N_{+}\left(E_{F}\right)+N_{-}\left(E_{F}\right)}\right| 100 \%$, the polarization degree of electrons at the Fermi level can be determined. Thus, the $\left(\mathrm{Fe}_{1-x} \mathrm{Ni}_{x}\right)_{2} \mathrm{P}$ can be classified as the highly spin-polarised system with the $P$ factor above $80 \%$ (Fig. 1) in the range of $0.0<x<0.15$, reaching at maximum $P=82 \%$ for $\left(\mathrm{Fe}_{0.9} \mathrm{Ni}_{0.1}\right)_{2} \mathrm{P}$. This result closely relates to the anomalous behaviour of $R(T)$ curves with the maximum at $T_{\mathrm{C}}$, which is the most pronounced for $x=0.08$.

\section{Acknowledgments}

This work was sponsored by the Committee for Scientific Research through the grant no. 2 P302 10307.

\section{References}

[1] R. Fruchart, A. Roger, J.P. Senateur, J. Appl. Phys. 40, 1250 (1067).

[2] H. Fujii, Y. Uwatoko, K. Motoya, Y. Ito, T. Okamoto, J. Phys. Soc. Jpn. 57, 2143 (1988) and references therein.

[3] S. Ishida, S. Asano, J. Ishida, J. Phys. F, Met. Phys. 17, 475 (1987).

[4] L. Severin, L. Häggström, L. Nordström, Y. Andersson, B. Johnanson, J. Phys., Condens. Matter 7, 185 (1995).

[5] J. Toboła, M. Bacmann, D. Fruchart, S. Kaprzyk, S. Nizioł, J. Magn. Magn. Mater. 157-158, 708 (1996).

[6] H. Fujii, T. Hokabe, H. Fujiwara, T. Okamoto, J. Phys. Soc. Jpn. 44, 96 (1978).

[7] A. Bansil, S. Kaprzyk, J. Toboła, in: Applications of Multiple Scattering Theory to Materials Science, Eds. W.H. Butler, P.H. Dederichs, A. Gonis, R.L. Weawer, Symposium Proc., Vol. 253, materials Research Society, Pittsburgh 1992, p. 505.

[8] S. Kaprzyk, A. Bansil, Phys. Rev. B 42, 7378 (1990).

[9] Y. Maeda, Y. Takashima, J. Inorg. Nucl. Chem. 43, 41 (1977).

[10] Y. Nishino, S. Inoue, N. Kawamiya, A. Asano, Phys. Rev. B 48, 13607 (1993). 